\title{
The promotion of family wellness for refugee families in cultural transition - A phenomenographic study
}

\author{
Kerstin Samarasinghe ${ }^{1}$, Barbro Arvidsson ${ }^{2,3}$, Agneta Abrahamsson ${ }^{4}$, Bengt Fridlund ${ }^{5,6}$ \\ 1. School of Health and Society, Kristianstad University, Kristianstad, Sweden. 2. School of Social and Health Sciences, \\ Halmstad University, Halmstad, Sweden. 3. Institutt for Sykepleiefag, Högskolen i Gjövik, Gjövik, Norge. 4. FoUrum, \\ Research and development unit in county of Jönköping, Sweden. 5. School of Health Sciences, Jönköping University, \\ Jönköping, Sweden. 6. School of Health Sciences, Lund University, Lund, Sweden
}

Correspondence: Kerstin Samarasinghe. Address: School of Health and Society, Kristianstad University, Kristianstad, Sweden. Email: Kerstin.Samarasinghe@hkr.se

Received: December 30, 2011 Accepted: February 27, $2012 \quad$ Published: November 1, 2012

DOI : 10.5430/jnep.v2n4p92 URL: http://dx.doi.org/10.5430/jnep.v2n4p92

\section{Abstract}

Objective: To illustrate how nurses can promote family wellness and facilitate acculturation for involuntary migrant families as conceptualized by bilingual interpreters and cultural mediators with own past refugee experience. Due to the nature of involuntary migration and accompanying acculturation, refugee families face a complex transition, exposing them to vulnerability in cohesion and family function. Involuntary migrant health needs are largely managed within the Primary Health Care sector where Primary Health Care Nurses (PHCN) play an important role. Additionally, bilingual interpreters and cultural mediators with personal experience of being refugees and subsequent acculturation play a critical role in bridging the language and cultural gap between migrant families and PHCNs.

Methods: The study is descriptive and explorative in design with a phenomenographic approach. Data was collected in Southern Sweden utilizing in-depth interviews with ten bilingual interpreters and cultural mediators originating from the Balkans, Kurdistan, Eritrea and Somalia. A contextual analysis with reference to phenomenography was used in interpreting the data material.

Results: Three separate themes illustrated the meaning of family wellness: a sense of belonging to the new homeland, the maintenance of self-esteem and stable family interrelationships. The analysis demonstrated that the way ex-refugee bilingual interpreters and cultural mediators perceived of how to promote family wellness, fell into three qualitative different conceptions: (1) Promotion of family wellness is the responsibility of the family itself, manifested in its attitude in wanting to adjust to change, (2) Promotion of family wellness is the consideration of those outside the family and is marked by understanding and respectful attitudes, (3) Promotion of family wellness is a societal responsibility to which successful integration is a prerequisite.

Conclusions: The promotion of health of involuntary migrant families in cultural transition is complex due to families, other members of the society and society at large all contributing to family wellness in the process of acculturation. For nurses to facilitate a healthy transition for involuntary migrant families, a holistic approach working with the entire family in a psychosocial way and cooperating with other health care professionals, community authorities and ethnic organizations maybe a future direction in encounters with involuntary migrant families with health problems. Adopting a family system approach will enable nurses to provide culturally and transition-competent quality care by enabling stabilizing interfamily relationships through supportive conversations about changes and its subsequent reactions and 
possible coping of the family as a unit. Further research in order to enhance health promotion would preferable take on a participatory approach.

\section{Key words}

Refugee, Cultural transition, Family wellness, Heath promotion, Phenomenography

\section{I ntroduction}

Involuntary migration, as caused by war and political upheaval, and any subsequent cultural transition is a known challenge to family wellness ${ }^{[1-3]}$; the situational change arising from migration gives rise to cultural transition and subsequent acculturation. Acculturation is a complex social and psychological process which implies cultural learning and behavioural adaptation of a non native country such as learning of a new lifestyle, the proficiency of a new language and absorption of different values ${ }^{[4]}$. Therefore acculturation imposes a transformation of identity and self-perception which may impact self-esteem and self-efficacy ${ }^{[5]}$ affecting the biochemical system of the body thus increasing the vulnerability to psychological distress; so called acculturative stress ${ }^{[6-8]}$.

From a family perspective, acculturation may give rise to changes in the distribution of family roles which according to Sluzki ${ }^{[1]}$ may escalate progressively into major crises of family inter-relationships. Additionally, family members are frequently unaware of the stressful nature of migration and its cumulative impact on family function. Aroian, Spitzer and Bell ${ }^{[9]}$ illustrated that family members can be overwhelmed by their own immigration demands and as such generate additional stress on family members. Families originating from collectivist oriented cultures seeking refugee in individualistic oriented countries are especially at risk for interpersonal conflicts due to changed family roles ${ }^{[3,10]}$. The literature on the impact of acculturation on family function and cohesion of involuntary migrant families is however complex and inconsistent. Whilst some studies show that these families were exposed to vulnerability both in family cohesion and to family function ${ }^{[3,11-13]}$ others do not find any evidence for such consequences ${ }^{[14]}$. However, the reunifications of family members were shown to be a risk factor to family function and cohesion ${ }^{[3,15]}$. In addition, post migration factors especially of socioeconomic and psychosocial concerns have also shown to be crucial to health in acculturating individuals and families ${ }^{[16]}$.

Sweden within a cultural context lends itself as an example of an individualistic oriented country with a pluralist society, as it is a recipient country for refugees in accordance with the United Nations guidelines. In 2008, approximately $13 \%$ of its 9.4 million populations originate from more than 200 countries ${ }^{[18]}$ of which $46 \%$ originate from non-European countries ${ }^{[19]}$. By 2060 it is thought that approximately $18 \%$ of the population of Sweden will be foreign-born originating mainly from non-European, collectivistic countries ${ }^{[18]}$.

Empirical studies in Sweden have shown that contextual socio-environmental stressors such as social degradation, racism and loss of financial control, increased the vulnerability to psychological distress and physical disease in involuntarily migrated families ${ }^{[7]}$. Nyberg ${ }^{[20]}$ found that loss of self-image was shown to be an emotional threat in Chilean families. The high divorce rate in Iranian families in comparison to native Swedish families were attributed to worse socio-economic circumstances, acculturative stress and a changed function of the traditional male role ${ }^{[20]}$. Factors such as living in uncertainty awaiting asylum, having unprocessed traumas, facing unemployment, changed roles within the family, perceived unfriendly attitudes of the host country and social segregation within Swedish society, were conceived as stressors causing mental distress, physical disease and family conflicts, according to involuntarily migrated families living in Sweden ${ }^{[21]}$. Similarly Samarasinghe, Fridlund and Arvidsson ${ }^{[22]}$ have described the complexity of the relationship between the socio-economic status of involuntary migrant families, the receiving and encountering of different factors in Swedish society and the mental health of these families from the perspective of Primary Health Care Nurses (PHCN), as the PHCN is most often the involuntarily migrant family’s first contact with the Swedish health care system. 
However, nurses who frequently interact with involuntary migrant families play a vital role in promoting health and preventing illness of these families. As transitions impact on emotional and physical wellbeing ${ }^{[23]}$, cultural transition and the subsequent acculturation should form a part of nurse's preventive care. Facilitating cultural transition is however new to nursing which motivates research to achieve a comprehensive and genuine understanding of the promotion of involuntary migrant families` health whilst in the process of acculturating.

A family perspective was adopted in this study since involuntary migrant families in Sweden mostly originate from collectivistic oriented cultures. The concept of family has a wide range of definitions in a cross-cultural perspective but none that has been cross-culturally accepted and universally applicable ${ }^{[24]}$. Neuman \& Fawcett ${ }^{[25]}$ defines family as a group of two or more persons who create and maintain a common culture and whose most central goal is one of continuance. Furthermore, they equated health with wellness defined as the condition in which all parts and subparts referring to physiological, psychological, developmental, socio-cultural and spiritual variables are in harmony with the whole of the individual as well as with the whole of the family. From a wellness perspective it is therefore crucial to acknowledge the health status of the individuals of the family as well as of the family as a unit.

The focus of this paper is on how nurses can promote family wellness for refugee families' whilst they undergo acculturation and thereby facilitate their cultural transition. In order to gain a crucial understanding pertaining to cultural transition this study drew from the experiences of bilingual and cultural mediators, who were former refugees having undergone cultural transition and subsequent acculturation themselves. Additionally, their experiences of bridging the cultural and language barriers between health personnel and immigrant families ${ }^{[26]}$ gave them a valuable perspective with regard to understanding the impact of acculturation on family wellness as well as thoughts around prevention of subsequent negative effects.

\section{Methods}

\subsection{Design and method description}

A qualitative design using phenomenography as the research approach was used. Phenomenography focuses on the variations of peoples' understanding of experienced phenomena in the world around them ${ }^{[27,28]}$. Conceptions are central to phenomenography as these often represent implied meanings which have not been subjected to reflection and made explicit ${ }^{[27]}$. As individuals conceptualize a phenomenon differently due to their culturally and socially dependant pre-understanding of the phenomenon, the outcome of the contextual analysis related to phenomenography, will therefore result in a spectrum of meanings ${ }^{[29]}$.

\subsection{The context of the study}

The study took place in the South of Sweden. The largest groups who sought asylum in Sweden in 2008 were citizens of Iraq and Somalia ${ }^{[18]}$. Family reunification of refugees is currently the most common reason for immigration to Sweden. Members of families from Iraq, former Yugoslavia and Somalia were the largest group of relative immigrants during $2006{ }^{[30]}$. Asylum-seekers are offered a free health examination upon arrival and interpreting services are provided within the PHC. Once a permanent resident permit is obtained, the family has the same rights to receive health care as Swedish citizens $^{[31]}$.

\subsection{Participants}

Ten bilingual interpreters and cultural mediators all of whom themselves were former refugees were strategically chosen in accordance with phenomenography to embrace the variation of conceptions ${ }^{[32]}$. As a consequence different backgrounds with regard to ethnicity, sex, education, religion and number of years of life spent in Sweden were covered (see Table 1). All participants had interpreted for a minimum of 100 involuntary migrants. Inclusion criteria were that the 
interpreter or mediator had personal experiences of involuntary migration and originated from Bosnia, Kosovo-Albania, Kurdistan, Eritrea and Somalia. These countries were strategically chosen with reference to physiognomy and cultural values which were similar and different to the Swedish inhabitants according to a study by Westin ${ }^{\text {[33] }}$.

Table 1. Socio-demographic characteristics of the informants $(\mathrm{N}=10)$

\begin{tabular}{|c|c|c|}
\hline Country & & \\
\hline & Bosnian/Eritrea/Kosovo-Albania & $2 / 2 / 2$ \\
\hline & Kurdistan/Somalia & $2 / 2$ \\
\hline Sex & & \\
\hline & Female/male & $5 / 5$ \\
\hline Type of & interpreter & \\
\hline & $\begin{array}{l}\text { Bilingual interpreter/Bilingual interpreter and } \\
\text { cultural mediator }\end{array}$ & $5 / 5$ \\
\hline Number & of years as an interpreter & \\
\hline & Mean (range) & $5(2-15)$ \\
\hline Age in $y$ & ears & \\
\hline & Mean (range) & $44,5(27-55)$ \\
\hline Period a & waiting asylum in months & \\
\hline & Mean (range) & $10,5(4-48)$ \\
\hline Number & of years in Sweden & \\
\hline & Mean (range) & $16(6-17)$ \\
\hline Educati & & \\
\hline & Upper secondary school/University & $4 / 6$ \\
\hline Religion & & \\
\hline & Muslim/Orthodox & $8 / 2$ \\
\hline
\end{tabular}

\subsection{Data collection}

Data was collected by the first author who is a district nurse cum lecturer in nursing. The methodology used was narrative and tape-recorded in-depth interviews, each in Swedish and lasting approximately three hours with the location of each interview chosen by the participant. The interviews were based on a map presenting a typology of family profiles epitomizing the health characteristics of a migrated family in transition ${ }^{[21,22]}$ (see Figure 1). The starting point of each interview was: how do you perceive the family profiles presented, followed by the question: how best can the promotion of family wellness be achieved while adjusting to their life in Sweden? In order to obtain further dept to the participants' statements, follow-up questions were used. For example, can you elaborate on your thoughts? How would you describe this in more detail? All interviews were transcribed ad verbatim.

\subsection{Ethical considerations}

The study was performed in accordance with the principles of Helsinki and was approved by the Ethics Committee at Lund University, Sweden (LU 445-03).

\subsection{Analysis}

The analysis was conducted by the primary author while the remaining authors served as additional evaluators in the categorization procedure. The analysis was carried out in five steps in line with contextual analysis ${ }^{[29]}$ : (1) the transcribed interviews were read several times to obtain a sense of the whole, (2) an analysis of each interview was carried out in search of statements relating to "What" expressing the participants' conceptions of family wellness and "How" expressing the participants ways of talking about the measures to target family wellness, (3) The What and the How were subsequently summarized in each interview and three distinguishing themes were identified; belonging to the new homeland, maintaining self-esteem and stabilizing family relationship, (4) the summaries were differentiated and grouped together in qualitatively distinct categories based on similarities or differences of the identified themes, (5) The completed 
picture of the categorized data was demarcated into a system of three qualitatively different categories of description based on how the identified themes varied from each other (see Table 2). Since each descriptive category constitutes a conception of the phenomenon on a collective level each participant could be represented in all the categories of description.

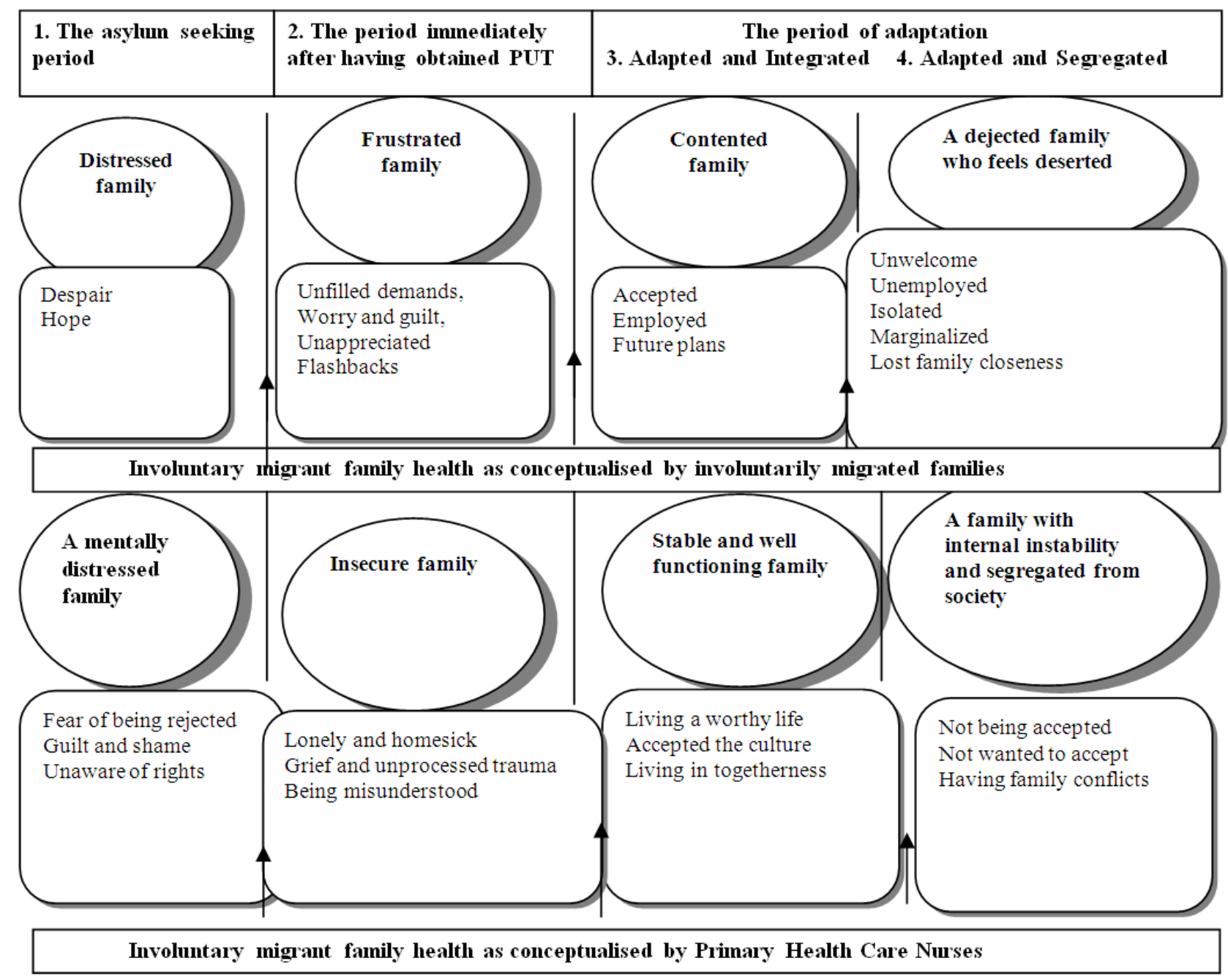

Figure 1. Family wellness of involuntary migrant families in cultural transition

Table 2. Outcome space of how to promote family wellness

\begin{tabular}{|c|c|c|c|}
\hline Themes & $\begin{array}{l}\text { The family's own } \\
\text { responsibility }\end{array}$ & $\begin{array}{l}\text { The consideration of others } \\
\text { outside the family }\end{array}$ & A societal responsibility \\
\hline $\begin{array}{l}\text { Belonging to the new } \\
\text { homeland }\end{array}$ & $\begin{array}{l}\text { Positive thinking ; focusing } \\
\text { on opportunities }\end{array}$ & $\begin{array}{l}\text { Understanding and } \\
\text { respectful attitudes }\end{array}$ & Integrated in society \\
\hline Maintaining self-esteem & $\begin{array}{l}\text { Affiliating dual cultural } \\
\text { identity }\end{array}$ & $\begin{array}{l}\text { Recognition and affirming } \\
\text { ones cultural values }\end{array}$ & Utilizing immigrants' competences \\
\hline $\begin{array}{l}\text { Stabilizing } \\
\text { interrelationship }\end{array}$ & $\begin{array}{l}\text { Striving to understand and } \\
\text { support each other }\end{array}$ & Outreaching activities & $\begin{array}{l}\text { Information about the functioning of } \\
\text { the new homeland }\end{array}$ \\
\hline
\end{tabular}




\section{Findings}

All participants agreed upon that the family profiles in Figure 1 illustrated the reality of living in Sweden as an involuntarily migrated family. The following conceptions were identified as forming parts in promoting family wellness during acculturation:

\section{Promotion of family wellness is the responsibility of the family itself, manifested in its attitude in wanting to adjust to change}

Family members' motivation and willingness to adapt to their new homeland characterized the main feature of this conception.

"It all depends on me and how I cope in adjusting to the new country; you have to become determined to manage and not to think negatively. You must have the courage and show that it is the self that really matters”. (Kosovo female)

The participants meant that the responsibility lay with the family to seize every opportunity to learn of the new home country in order to develop a sense of belonging; as in a case where a family invited their child's schoolteacher to come and speak to them about cultural norms. In a second case a father used the resources of the local library to study Swedish law and learn about duties and rights in Sweden. Moreover, the family members were conceived as needing mental adjustment by using positive thinking and putting their children's future in focus. A key element in facilitating the development of belonging for their children in the new home country was attributed to the avoidance of negatively comparing Sweden to the country of origin.

"Children who are growing up here have two different ways of thinking, one at home and another one at school; they have a different life together with their friends. That is why parents must listen and not say to their children that everything is forbidden”. (Kurdish male)

This group of participants however expressed that it was beneficial for one's self-esteem to have dual cultural affiliation, especially for children. By discussing the difference between the two countries in regards to lifestyle and cultural norms parents could aid this process. Additionally, actively using existing cultural organizations as a support network was conceived to be a positive, allowing for the maintaining of ethnic identity whilst providing opportunities to learn about the new culture. An example of this was made where the Eritrean society organized work shops for teenagers exploring the particular issues that they may face as part of their transition into the new society whilst maintaining their Eritrean heritage.

For a family to maintain stability and cohesion throughout the adjustment period these participants meant that the family must strive to understand and support each other in spite of changing family roles. The example of a wife, who is patient towards her husband despite his lost status as the breadwinner of the family, was quoted frequently. Likewise, the husband must offer support to his wife as she has lost her social network and the support she use to get from other women in the former homeland. It was also considered important that the man takes his wife's views into account in a democratic way before any decisions are made. From a parents point of view it was important that the parents' problems should not be discussed in the presence of their children, because it was perceived to cause insecurity in children. This was particularly important during asylum period.

Furthermore, it was thought helpful for parents to be observant as to whom their children associated with whilst making appropriate demands and setting clear limits so as to offer a firm structure. As part of this however, it was believed that understanding the children's particular needs during acculturation was of utmost importance. For instance, it was thought vital to provide the children with an allowance similar to what Swedish children typically received so as to prevent the children being alienated amongst their peers. 
"We ourselves have to be strong otherwise it will not work. There are so many possibilities in Sweden if we only can see them but you can not just sit and wait for them. I myself need to struggle to adapt to the new country in order that my children will feel good and not feel alienated in society. It is all dependent on yourself and you can not organize any assistance in facilitating this adjustment”. (Eritrean female)

\section{Promotion of family wellness is the consideration of those outside the family and is marked by understanding and respectful attitudes}

This conception was characterized by the community showing understanding and respectful attitudes in encounters with the involuntary migrated families.

"It is the first step to feel at home knowing that there is someone who cares about me, it feels just like the relationship between mother and child and it's very important”. (Kosovo female)

Early contacts with native Swedes were conceived as supporting the development of a sense of belonging to the new homeland. Pensioners were viewed as beneficial in this respect, especially in cases of immigrant women with little or no formal educational as they were perceived to feel secure in the company of elderly women. Similarly, it was suggested that a group of schoolmates could be helpful to younger members of the family in facilitating acculturation by functioning as language and social instructors at school. The local area network groups that exist in Sweden, operating on a voluntary basis and seeking to improve health within communities was conceived to be an important source in order to arrange informal and formal support contacts between native Swedes and immigrant families.

Self-esteem enhancing actions were conceived to include such as a kind reception by health care personnel where the emphasis on treating the patient with respect and dignity were at times thought to have a larger healing impact than medicine even.

"When I meet somebody who can encourage me for instance here at the health centre there is a nurse who talks to me in such a way that I felt well - but with another nurse it was not the same. You have to have a special attitude, and then it works $75 \%$ better than medicine”. (Eritrean male)

Furthermore, sensitivity toward cultural differences and the importance for the patient to feel their ailments were taken seriously was conceived important. For instance where complaints and symptoms could be culturally inflicted as in the cases of women who have undergone female circumcision complaining of menstrual disorders and where it was key to offer immediate treatment rather than propose self-care.

"It's the biggest thing that someone believes in you when you have problems with your health or problems with family or anything. If you get someone who believes in you, it’s a huge part of yourself and your life”. (Somali female)

Finally, simple everyday questions such as "How are you today?” and "What can I do for you?" was conceived as beneficial to strengthening self-esteem and encouraging individuals to open up and express thoughts and feelings.

Outreaching activities such as social visits by persons within the community and health workers was felt to be principal in strengthening the feeling of acceptance in the new homeland which in turn was thought to enhance family members' support of each other; thus stabilizing the family as a unit.

"It all depends on how you have been received, if one is received with trust and in a good way you are able to reveal your actual feelings and thoughts. Such contacts as coming and knocking at the door and making us feel welcome could greatly help positively in holding families together. This would help the families not to split up and have a deeper conflict situation”. (Bosnian male) 


\section{Promotion of family wellness is a societal responsibility to which successful integration is a prerequisite}

The overriding feature to this conception was that family wellness could be achieved by integrating the families into society. The participants felt that it was the responsibility of society to establish necessary conditions for integration in cooperation with immigrants.

The families ought to "get a place" in the society and employment was seen as the foremost approach in assisting the development of a sense of belonging to the new homeland. Employment was also seen as enabling economic independence thus enhancing control of one's own life as well as enhancing parents' ability to provide for their children in a similar way as a large part of native Swedish parents.

"The best help is a job as this is necessary for the parents to feel that they are integrated into society. This is important not only for the parents but even more for the children”. (Bosnian female)

In order to maintain self-esteem an individualized language education was considered essential taking into account different persons learning capabilities as learning Swedish was conceived as necessary for the family to integrate. Similarly, for children not to feel alienated home country language classes should take place outside school hours and not at the expense of other school subjects as is the current norm. This was conceived as discrimination by treating the children differently from their schoolmates. The maintenance of self-esteem could further be facilitated by encountered personnel's prior experience of being a refugee according to the participants as their experiences of acculturation were conceived as having a calming effect on acculturating families.

To obtain a smoother transition and a faster adjustment to the new life situation it was thought to be important that the families receive support by cultural mediator during the first five years. This was exemplified by a case where the parents were prohibiting their daughter from attending a school camp was used and where the intervention of a cultural mediator resolved the situation.

Information about Swedish society and its roles and functions, for instance the role of social allowances where the parents were unable to obtain employment, was conceived as an essential element to the alleviation of stress within the family. Study circles, multilingual newspapers and local radio broadcasts were suggested as ways of facilitating the obtaining of societal information which in turn was viewed as essential to avoid the formation of prejudices against the new culture.

"It is only through providing more information about the society we are living in and how this society functions that any prejudice can be alleviated ...one thinks differently here (in Sweden), and one has more freedom to move about here in Sweden, children are not like ours but they too have parents who put limits on their children and not everybody is allowed to speak or do as they like”. (Kurdish female)

On an interrelationship basis, it was thought of as positive, where possible, for both husband and wife to obtain employment as this would allow for both to actively experience the new culture which in turn allowed for a parallel acculturation. However it was also conceived as important that the father ought to be able to support the family financially in order to uphold the stability of family interrelationships. This group of participants also meant that it was imperative that parents be allowed to keep their parental roles from the origin country, using language such as 'parents should be allowed to act as parents' to illustrate a more traditional parenting role than they perceived Sweden to have.

"I noticed what happened in Paris some years ago when teenagers went havoc and when the president said OK now it is enough, let the parents take over and then it all stopped. Give the parents the parental-role to play!” (Somali male)

This was of importance where they felt children attempted to gain an upper hand in the interrelationship roles toward the parents. Here they felt in the cases where social authorities intervened in families, that was vital to consider both the 
children's and the parents viewpoints and not, as they conceived the current reality to be just of the children. They thought it was wrong that authorities had the power intervene actively between the parents and their child.

"It's wrong if somebody should come between my child and me. If there are problems with parental child relations they are not solved by taking the children from the family. Instead they should listen to both sides-meeting the parents and the children together and not separately”. (Somali female)

Moreover the participants meant that the asylum period ought to be shortened in order to alleviate parental stress which was conceived as harmful to the mental health of the children as well as to the wellness of the family unit.

"The authorities should show more consideration to people coming from different countries and should co-operate with the immigrant organizations. They will not succeed in integration without this co-operation - if one only talks about integration but does nothing about it, it will stop there and there will not be any integration”. (Kosovo male)

\section{Discussion}

In this article, the joint effort between the families, other members of the society and society at large is all seen as contributing to family wellness in the process of acculturation of involuntary migrants. A resistance towards acculturation in cases of sudden and unplanned migration may however influence negatively on the families own motivation to adjust and adapt to a new homeland and its culture. The involuntary migrants' common dream of returning to the home country someday ${ }^{[34]}$ is an important part of the involuntary refugee's makeup which can make the acceptance of a new culture and habits even more difficult. These obstacles in the families together with obstacles from the community and the society at large ought to be faced in facilitating a healthy transition. Nurses can be a part in this by using a more systematic and deliberate way of encountering involuntary migrants with health problems.

In descriptive category, promotion of family wellness is the responsibility of the family itself, the involuntary migrant families themselves, was seen as responsible for managing their acculturation. This corroborates with Muecke ${ }^{[35]}$ who objects to literature presenting involuntary migrant families as vulnerable and victims rather than extraordinary resilient due to the fact that they had the courage and strength to leave their homeland. For nurses to facilitate involuntary migrants' perception of themselves as resilient, the nurse should use a salutogenic approach ${ }^{[36]}$ in interacting encounters, by focusing on the family's strengths, resources and possibilities. One way is to highlight compensatory resources for health outside the family as meeting places in the community and other information sources in the society as a whole. A salutogenic approach could also be shown by an understanding and a respectful attitude towards migrants' feelings of belonging as descriptive category in promotion of family wellness is the consideration of those outside the family.

Furthermore, the recognition and acceptance of cultural differences by other community members, was also conceived as enhancing self-esteem. Immigrants' feeling at ease with both cultures enables a subjective sense of well being which is in line with one of Schumacher and Meleis' three indicators of a healthy transition; a subjective sense of wellbeing, mastery of new behaviours and the well being of interpersonal relationships ${ }^{[23]}$.

A common need at the early stage in improving family wellbeing is having access to one's own culture in the host country. The relationship between increased self-esteem and a higher level of acceptance by other community members of the new home country was also highlighted by Nesdale et al. ${ }^{[37]}$. Since culture is most natural for all humans, as in Daun ${ }^{[38]}$, who's coinage "cultural is natural" implies that culture is universal and therefore has to be mutually recognised and acknowledged. The hallmark of a successful acculturation results in bicultural skills with a sense of belonging in both the new and the old culture ${ }^{[39,40]}$. Consequently, the families themselves cannot exclusively adapt to the new culture, but have to live with the cultural belief system of both the former and the new home land. Nurses may therefore facilitate a "healthy" transition by incorporating and valuing cultural components of both the country of origin as well as of the new 
country and thereby enable an integrated identity. However and additionally, in order to enhance family members' integrated identity, cultural issues ought to be acknowledged not only by the family and the nurse, but also by others outside the family as well as the society at large.

For nurses to become competent in promoting a subjective sense of well being in acculturating individuals, education must therefore provide an understanding of how cultural norms and attitudes as well as verbal-and nonverbal communication are transferred and embedded in individuals. This happens through the process of enculturation, which may simply be explained as "cultural programming" which aims to socialize the individual to be a good corporate citizen or a so called adaptive adult ${ }^{[41]}$. An understanding of this process will help nurses to explore the cultural belief system of the family thus helping them to make their enculturation explicit. This is an important aspect of the promotion of family wellness since several studies have shown that communicating immigrants' cultural belief systems has a positive impact on family wellness ${ }^{[42,43]}$. Also Bourdieu ${ }^{[44]}$ claims that communicating culturally inherited experiences or collective memories, so called habitués, is especially important since the awareness of one's own culture is most often implicit. In order to promote compliant healthcare involuntary migrant families should therefore be encouraged to communicate their belief systems in health matters.

However, since acculturation is a two-way process between involuntarily migrated families and the native population of

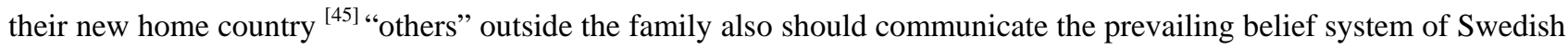
culture patterns. Only then will it be possible for immigrants to understand and learn the mastery of new behaviours, in line with Schumacher and Meleis' indicator of a healthy transition ${ }^{[23]}$. Furthermore, early contacts with native Swedes may promote acculturation as a two-way process in promotion of family wellness, respectful attitudes from the Swedes along with proper and elucidative information regarding the functioning of the new home country is a prerequisite and a societal responsibility for a successful integration. Various intermediating services can contribute in facilitating the two-way process in acculturation. In a community intervention, "bridge-builders" contributed with successful social interactions ${ }^{[46]}$. Further social interactions may be encouraged in line with Elmeroth ${ }^{[47]}$ who emphasized the importance for illiterate adults to have greater contact with language speakers. The participants of this study suggested local community support groups as important in facilitating social contacts. We suggest nurses to collaborate more with local voluntary network groups, ethnic organisations and the social authorities in order to promote a better social interaction between native Swedes and involuntarily migrated families. This conclusion corroborates with Samarasinghe, Fridlund \& Arvidsson ${ }^{[48]}$ who demonstrated that PHCN who had a holistic approach in their health promotion of involuntary migrated families by cooperating with different organizational structures and systems of society, helped in improving the wellness of acculturating families.

Other factors outside the reach of nurses that are related to social pre-requisites with implications for family wellness amongst involuntary immigrants should be handled differently. For instance a short but meaningful asylum period can, in line with Sourander ${ }^{[49]}$, contribute to a lower level of stress and less psychiatric symptoms in refugee families. Moreover, employment was conceived as supportive of stable interfamily relations and facilitating integration by enabling the family to actively participate in society. Effective health promotion interventions ought to take into consideration the dynamic relationships between evolving policies that fail to directly address barriers to wellness such as unemployment and a prolonged waiting for residence permits as described in the descriptive category; promotion of family wellness is a societal responsibility, to which successful integration is a prerequisite. These factors are not easy for nurses to act upon unless nurses move into the socio-political arena by uncovering external conditions that may create constraining forces towards the achievement of a healthy transition.

\subsection{A systemic approach in promoting family wellness}

In developing the cultural transition for involuntary migrant families into what Schumacher and Meleis ${ }^{[23]}$ name a healthy transition, all three conceptions - the family, others outside the family and the society - could be seen as the main 
objectives. In encounters with involuntary immigrants nurses must therefore adopt a holistic approach by cooperating with other healthcare professionals, community authorities and ethnic organizations.

A systemic approach to promotion of family wellness is to implement family focused nursing in order to enable the family to understand how acculturation may impact individually on the wellness of the family members as well as on the family as a unit. Since the family encompasses members other than those living in Sweden, the use of a genogram would be helpful in identifying the family as a whole ${ }^{[50]}$. Georgas ${ }^{[24]}$ who suggested that many cultural patterns in family life would continue to exist despite changes due to acculturation further supported this. The use of an ecomap will help in illustrating the structure, function and developmental life cycle of the family ${ }^{[50]}$. It will further help in depicting interaction within the family and between families and the community. To enhance family cohesion, nurses need to support the family to talk about their acculturation experiences focusing on changes in family roles as well as the role of the parent. Nurses who establish a relationship with the family through outreaching activities such as home visits as shown in the descriptive category; promotion of family wellness is the consideration of those outside the family may further support the strengthening of family relationships which are yet another indicator of a healthy transition according to Schumacher \& Meleis ${ }^{[23]}$.

\subsection{Methodological issues}

Limitations of the study refer mainly to that the participants' primary role unlike the PHCNs was not responsible for family wellness and therefore lacked self-perceived experiences of health promotion. However, phenomenography enables the participants to make implied meanings explicit by reflecting upon their experiences ${ }^{[30]}$ and was therefore considered as an applicable research approach in this study. As for transferring the result of the study to similar situations one may consider contextual issues that are never static but constantly changing. Receiving and caring for refugees from all over the world, especially from non European countries, are relatively new experiences in Sweden, which limit the transferability of the findings. However, each conception of the findings is an objectified abstraction representing a central meaning on a collective level, which makes the findings transferable to similar contexts.

\section{Conclusions}

The promotion of health of involuntary migrant families in cultural transition is complex due to families, other members of the society and society at large all contributing to family wellness in the process of acculturation. Therefore for nurses to facilitate a healthy transition for such families, a holistic approach of nurses working with the entire family in a psychosocial way and cooperating with other health care professionals, community authorities and ethnic organizations may therefore be the future direction in encounters with involuntary migrant families with health problems. Adopting a family system approach will thus enable nurses to provide culturally and transition-competent quality care by stabilizing interfamily relationships during acculturation, through supportive family conversations with the family unit in a careful and sensitive manner about the family's transition experience with regard to changes, subsequent reactions and coping strategies. Further research in order to enhance health promotion would preferable take on a participatory approach. Involuntary immigrants can thereby contribute with their unique experiences and knowledge in order to gain a deeper and more inclusive understanding of the complex dynamics operating within acculturating families.

\section{Acknowledgements}

The authors wish to thank the interpreters and cultural mediators who participated in this study and Kristianstad University for financial support.

\section{Conflicting interests}

There are no interests of conflict to declare. 


\section{References}

[1] Sluzki CE. Migration and family conflict. Fam Process. 1979; 18 (4): 379-390. PMid:527699 http://dx.doi.org/10.1111/j.1545-5300.1979.00379.x

[2] Weine S, Muzurovic N, Kulauzovic Y, Besic S, Lezic, A, Mujagic A, et al. Family consequences of refugee trauma. Fam Process. 2004a; 43 (2): 147-58. PMid:15603500 http://dx.doi.org/10.1111/j.1545-5300.2004.04302002.x

[3] Bhugra D. Migration and mental health. Acta Psychiatr Scand. 2004; 109: 243-258. PMid:15008797 http://dx.doi.org/10.1046/j.0001-690X.2003.00246.x

[4] Sam DL. Acculturation: conceptual background and core components. In The Cambridge handbook of acculturation psychology. DL. Sam, JW. Berry eds, Cambridge: Press. 2006; 11-27.

[5] Berry JW. Immigration, acculturation, and adaptation. Appl Psychol Int-Rev. 1997; 46: 5-68.

[6] Berry JW, Kim U, Minde T, Mok D. Comparative studies of acculturative stress. Int Migr Rev. 1987; 3: 491-11. http://dx.doi.org/10.2307/2546607

[7] Sundquist J, Bayard Burfield L, Johansson LM, Johansson SE. Impact of ethnicity, violence and acculturation on displaced migrants: psychological distress and psychosomatic complaints among refugees in Sweden. J Nerv Ment Dis. 2000; 188(6):357-65. PMid:10890344 http://dx.doi.org/10.1097/00005053-200006000-00006

[8] Westermeyer J, Bouafuely J, Neider J, Callies A. Somatization among refugees: an epidemiologic study. Psychosomatics: J Acad Psychosomatic Med. 1989; 30: 34-43.

[9] Aroian K, Spitzer A, Bell M. Family stress and support among former Soviet immigrants. Western J Nurs Res. 1996; 18(6): 655-674. PMid:9000873 http://dx.doi.org/10.1177/019394599601800604

[10] Hanssen I. An intercultural nursing perspective on autonomy. J Nurs Ethics. 2004; 11: 28-41. PMid:14763648 http://dx.doi.org/10.1191/0969733004ne664oa

[11] Fox PG. Stress related to family change among Vietnamese refugees. Br J Community Nurs. 1991; 8: 45-56. PMid:1995784 http://dx.doi.org/10.1207/s15327655jchn0801_5

[12] Birman D. Acculturation gap and family adjustment. Findings with Soviet Jewish refugees in the United States and implications for measurement. J Cross Cult Psychol. 2006; 37(5): 568-589. http://dx.doi.org/10.1177/0022022106290479

[13] Spencer JH, Thao L. Parent refugee status, immigrant stressors, and Southeast Asian youth violence. J Immigr Minor Health. 2006; 8(4): 359-368. PMid:16841183 http://dx.doi.org/10.1007/s10903-006-9006-x

[14] Merali N. Family experiences of Central American refugees who overestimate intergenerational gaps. Can J Couns. 2004; 38: 91-103.

[15] Rousseau C, Rufagari MC, Bagilishya D, Measham T. Remaking family life: strategies for re-establishing continuity among Congolese refugees during the family reunification process. 2004; 59 (5): 1095-1108.

[16] Hondius AJK, van Willigen LHM, Kleijn WC, van der Ploeg LHM. Health problems among Latin-American and Middle-Eastern refugees in the Netherlands:Relations with violence exposure and ongoing sociopsychological strain. 2000; 13: 619-634.

[17] SCB, Statistics Sweden. Born in Sweden - but still different? The significance of parents' country of birth. Demographic reports. Stockholm; Forecasting Institute, Sweden. 2010; 2.

[18] Swedish Migration Board (SMB). Annual report. http://www.migrationsverket.se/download/18.46b604a812cbcdd7dba800023153/\%C3\%85rsredovisning_2010. pdf. (4 March 2011, date last accessed).

[19] Nyberg E. Migration of families with children. Family relations in a changed life situation. PhD thesis. Stockholm University, Department of Education, 1993 (In Swedish)

[20] Darvishpour M. Immigrant women who break establishment patterns: how changing power relations within Iranian families in Sweden influence relationships. PhD thesis. Stockholm University, Stockholm, Department of Sociology, 2003 (In Swedish).

[21] Samarasinghe K, Arvidsson B. `It is a different war to fight here in Sweden'- the impact of involuntary migration on the health of refugee families in transition 2002, Scand J Caring Sci. 2002; 16: 292-301. PMid:12191042 http://dx.doi.org/10.1046/j.1471-6712.2002.00089.x

[22] Samarasinghe K, Fridlund B, Arvidsson B. Primary health care nurses' conceptions of involuntarily migrated families' health. Int Nurs Rev. 2006; 53: 301-307. PMid:17083420 http://dx.doi.org/10.1111/j.1466-7657.2006.00498.x

[23] Schumacher K, Meleis A.Transitions a central Concept in nursing. J Nurs Scholarship. 1994; 26 (2): 119-127. http://dx.doi.org/10.1111/j.1547-5069.1994.tb00929.x

[24] Georgas J. Families and family change. In Families across cultures J.Georgas, JW Berry, FJR.Van der Vijver, C. Kagitcibasi, YH. Poortinga eds, Cambridge: University Press. 2006; 3-51. http://dx.doi.org/10.1017/CBO9780511489822.002

[25] Neuman B, Fawcett J. The Neuman systems model, 5th ed.Upper Saddle River: Prentice Hall. 2010; 3-35. 
[26] Al-Krenawi, A, Graham, JR. The cultural mediator: bridging the gap between a non-western community and professional social work practice. Brit J Soc Work. 2001; 31: 665-685. http://dx.doi.org/10.1093/bjsw/31.5.665

[27] Marton F. Phenomenography-describing conceptions of the world around us. Instructional Science. 1981; 10: 177-200. http://dx.doi.org/10.1007/BF00132516

[28] Larsson J, Holmström I. Phenomenographic or phenomenological analysis: does it matter? Examples from a study on anaesthesiologists' work. Int J Qual Stud Health Well-being. 2007; 2: 55-64. http://dx.doi.org/10.1080/17482620601068105

[29] Svensson, L. Theoretical foundations of phenomenography. Higher Education Research \& Development. $1997 ; 16$ (2): $159-171$. http://dx.doi.org/10.1080/0729436970160204

[30] SCB, Statistics Sweden. Demographic reports.The future population of Sweden 2006-2060. Forecasting Institute Stockholm, Sweden 2009.

[31] National Board of Health. Health care for refugees and asylum seekers. Stockholm; General guidelines from the National Board of Health Care. 1995; 4.

[32] Fridlund, B. \& Hildingh, C. Qualitative research methods in the service of health research. Lund: Studentlitteratur. 2000; 13-24.

[33] Westin C. The tolerant opinion. Stockholm: CEIFO, 1987.

[34] Eastmond, M. Transnational returns and reconstruction in post-war Bosnia and Herzegovina. Int Migr. 2006 ; 44 (3): $141-166$. http://dx.doi.org/10.1111/j.1468-2435.2006.00375.x

[35] Muecke MA. New paradigms for refugee health problems. Soc Sci Med. 1992; 35: 515-523. http://dx.doi.org/10.1016/0277-9536(92)90344-P

[36] Antonovsky A. The salutogenic model as a theory to guide health promotion. Health Promot Int. 1996 ; 11 (1): 11-18. http://dx.doi.org/10.1093/heapro/11.1.11

[37] Nesdale D, Rooney R, Smith L.Migrant ethnic identity and psychological distress. J Cross-Cult Psychol 1997; 28 : 569-588. http://dx.doi.org/10.1177/0022022197285004

[38] Daun, Å. The humanitarian and the culturally significant. (In Swedish). Stockholm: Prisma, 1999.

[39] Oppedal B. Development and acculturation. In The Cambridge handbook of acculturation psychology, DL.Sam, JW. Berry, eds. Cambridge: University Press. 2006; 97-113.

[40] Berry J.W. Acculturation: Living successfully in two cultures. Int J Intercult Relat. 2005; 29(6): 697-712. http://dx.doi.org/10.1016/j.ijintrel.2005.07.013

[41] Roer-Strier D. Socialization in Changing Cultural Contexts: A Search for Images of the “Adaptive Adult”. Soc Work. 2001; 46(3): 215-228. PMid:11495367 http://dx.doi.org/10.1093/sw/46.3.215

[42] Weine SM, Ware N, Klebic A. Converting cultural capital among teen refugees and their families from Bosnia-Herzegovina. Psych Serv. 2004b; 55 (8): 923-927. PMid:15292542 http://dx.doi.org/10.1176/appi.ps.55.8.923

[43] Merali N. Perceived experiences of Central American refugees who favourably judge the family's cultural transition process. Int JAdv Counsell. 2005; 27 (3): 345-357. http://dx.doi.org/10.1007/s10447-005-8198-4

[44] Bourdieu P. The Logic of Practice. Cambridge: Polity Press, 1990.

[45] Ward C, Fox S, Wilson J, Stuart J, Kus L. Contextual Influences on Acculturation Processes: The Roles of Family, Community and Society. Psychological Studies. 2010; 55(1): 26-34. http://dx.doi.org/10.1007/s12646-010-0003-8

[46] Abrahamsson A, Andersson J, Springett J. Building bridges or negotiating tensions? Experiences from a project aimed at enabling migrant access to health and social care in Sweden. Diversity in Health and Care. 2009; 6: 85-95.

[47] Elmeroth, E. From refugee camp to solitary confinement: illiterate adults learning Swedish as a second language. Scand J Educ Res. 2003; 47 (4): 431- 449. http://dx.doi.org/10.1080/00313830308593

[48] Samarasinghe K, Fridlund B, Arvidsson B. Primary health care nurses' conceptions of involuntarily migrated families' health. Int Nurs Rev. 2010; 57: 224-231. PMid:20579158 http://dx.doi.org/10.1111/j.1466-7657.2009.00790.x

[49] Sourander A. Refugee families during asylum seeking. Nord J Psychiat. 2003; 57(3): 203-207. PMid:12775295 http://dx.doi.org/10.1080/08039480310001364

[50] Wright LM, Leahey M. Nurses and Families. A guide to Family assessment and Intervention. 5th ed. Philadelphia: FA. Davis Company. 2000; 1-143. 